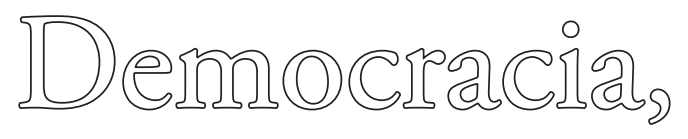

\title{
memoria y universidad hacia una educación ciudadana ${ }^{1}$
}

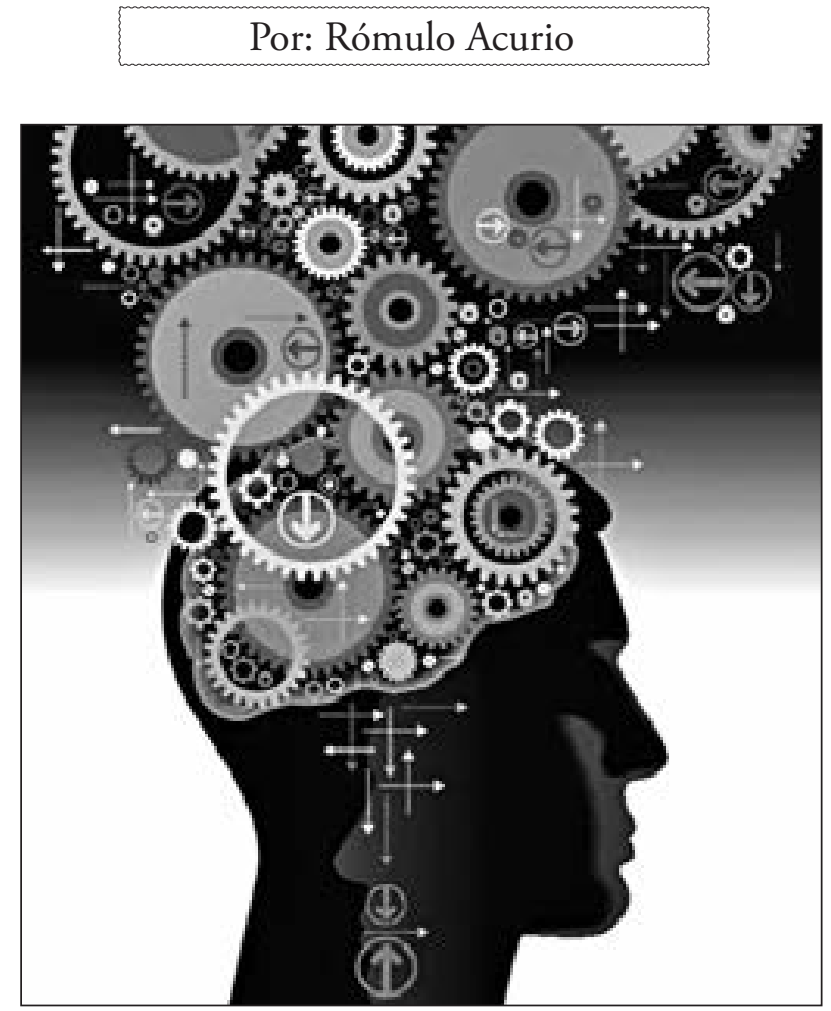

El trabajo incide en el modo cómo influye la cultura en nuestra forma de imaginar y en nuestro modo de recordar. Estas dos formas son importantes para la sociedad peruana; la educación es un apoyo dentro de esta problemática puesto que permite la ampliación de la libertad cultural. Se indica también que el Perú debe tomar en cuenta la comunidad y tener el derecho de respetar la identidad cultural (de aquello que queremos dentro de nosotros mismos), pero también de conformar una cultura compartida hacia adelante, hacia la "cultura global", hacia la libertad de arraigo y de desarraigo. ${ }^{1}$

Palabras claves: cultura, imaginación, recuerdo, memoria, educación, identidad, arraigo, desarraigo, universidad.

\section{¿Qué ocurre con la cultura mundial hoy en día?}

Hay muchas respuestas: sociológicas, antropológicas y filosóficas; sin embargo, quisiera resaltar algo que todos vemos a diario. Existen diversas opciones: el

1 Transcripción de la conferencia ofrecida por el poeta y filósofo Rómulo Acurio con motivo de la inauguración del Primer Semestre Académico de la URP. (marzo, 2014). cine, el internet, la radio, la televisión, las redes sociales donde se produce una asociación muy rápida que nos apabulla el día fácilmente. Al mismo tiempo, nosotros tenemos poco tiempo, poca energía, pocas ganas de detenernos a pensar, a asimilar las cosas que hacemos. El resultado es que al final, donde estemos, ya sea en Lima o en Tokio, terminamos hablando de las mismas cosas; terminamos teniendo las mismas ideas. Es una situación bastante peculiar.

Pero ¿qué es la cultura hoy día? Es un conjunto de películas, creaciones, video juegos, conciertos, libros; son todas esas cosas valiosas, importantes, divertidas, inteligentes; son todas esas cosas atractivas que muy bien las tocaría el músico.

¿Es eso la cultura o es algo más profundo? Es todo aquello que tenemos dentro de nuestras conciencias: los valores, las sensaciones, las certezas, los sentimientos, es decir, algo que no podemos coger, algo que está dentro de nosotros. Es importante hacer la distinción entre esas definiciones. En la primera, la cultura es un bien 
creativo, un bien que consumimos frecuentemente. En la segunda la cultura es un bien que forma parte de nosotros, que está siempre en nosotros, que vive en nosotros, en nuestras formas de ser.

Esta distinción es importante para los estudiosos porque -como piensan muchos- la cultura viene del consumo, de cómo un acto de conseguir cosas se va imponiendo en el mundo de hoy. La otra se refiere a un bien interior.

Para algunos autores esto tiene como consecuencia el debilitamiento de dos capacidades: la de imaginar y la de tener la capacidad de recordar. Me refiero a la capacidad de la imaginación, a esa habilidad que tenemos de proyectarnos, de interpretar, de vislumbrar, de soñar, de transformar nuestra experiencia en algo que cambia nuestro modo de ver el mundo y a nosotros mismos. Hoy en día el mundo es un escenario de combate, de guerra. Hay una competencia de distintos focos, de distintos conductores que desean capturar nuestra imaginación. Es lo que llamamos la cultura industrial.

En la industria cultural están los estudios de cine, las series de televisión, las empresa de redes sociales, las editoras, los creadores de video juegos; son todas las empresas que buscan capturar, seducir; sin duda son el poder dominante en este mundo. Es el estado jurídico con sus grandes empresas culturales. Hay, también, varios poderes en competencia: la industria del cine, la música, las culturas europeas, la producción de animación, la producción de música y telenovelas latinas; son todos productores de cultura.

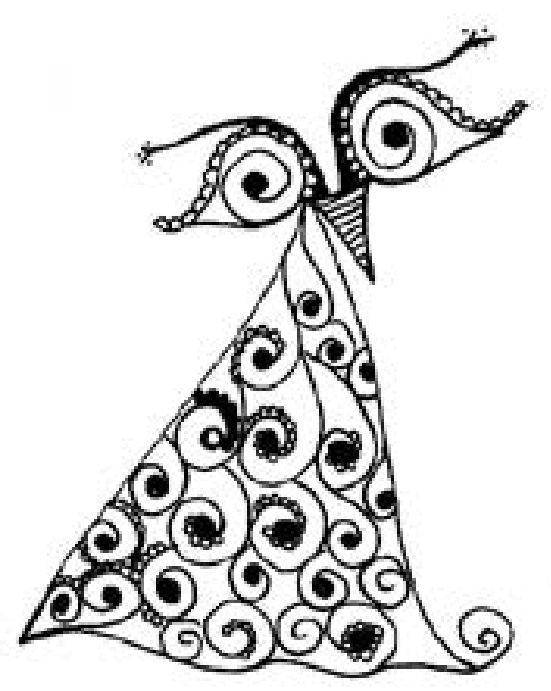

Un caso especial es la China que produce para su propio mercado de cine y televisión. Lo que hacen es copiar el mismo formato de cine y de televisión de los Estados Unidos y de Europa. En resumen, lo que en nuestra cultura global llamamos "mecanización". Pero también existe una diversificación tecnológica.

Las industrias culturales de los Estados Unidos absorben los talentos extranjeros. Los cineastas, guionistas y escritores le dan mucho espacio, incluso a lo que parece contracultural. Al mismo tiempo, las grandes empresas buscan presentar sus mercados en todo el mundo. Las grandes empresas que tienen su origen en los Estados Unidos son en realidad productos de los capitales de otras partes del mundo actuando contra los productores culturales locales.

Para algunos autores lo que ocurre es que hay una diversificación estandarizada, así que aunque parece que el mundo se diversifica en realidad todo se hace con un estrato más o menos uniforme. Lo que sucede, al parecer, es que hay muchos tipos de productos, hay una gran oferta, pero en realidad estos contenidos proyectan solo un modelo de individuo muy parecido al americano. El modelo dominante es el de un solo individuo, libre y sorprendente, que se hace a sí mismo, que no está solo en el pasado y que debe, a toda costa, divertirse en el limbo. Es una idea, sin duda, demasiado implícita de la autorrealización personal.

Sin embargo, nuestra imaginación está cada vez más calibrada por la idea muy poderosa del individuo que se transmite en la publicidad y el cine. Para muchos observadores esto hace que la cultura global no desarrolle la capacidad de imaginación de las personas, lo que nos empuja o alienta a consumir las mismas cosas, a sentir o pensar cosas similares a las que vemos en Japón, en Senegal.

Algo similar sucede con la otra capacidad: la memoria. Habría que preguntarse ¿qué es la memoria?: es el conjunto de rastros que no están presentes pero que podemos buscar en la conciencia; están escondidos. También la memoria es esa herencia guardada por la sociedad en la historia, los documentales, los objetos o las fotos de nuestra familia.

Al mismo tiempo uno puede preguntarse si la cultura actual se está formando con varios tipos de memoria. Por un lado seguimos construyendo nuestra "memoria racional" (familiar) y, en segundo lugar, formamos la "memoria comunitaria", la del barrio, la de nuestra ciudad, la de nuestro país. En esta memoria influye, 
por supuesto, lo que nos enseñan en el colegio o, también, lo que nos dicen los líderes de opinión, los líderes políticos en sus discursos.

Pero hay un tercer nivel de memoria que es la "memoria global" y esto es interesante resaltar. Al lado de la memoria personal, familiar y comunitaria se está desarrollando, cada vez más a través de la cultura como consumo, una memoria global. Muchas personas en el mundo empiezan a compartir esa memoria, sobre todo los más jóvenes. Dependiendo de nuestras edades, todos tenemos recuerdos grabados en nuestra mente y conciencia; por ejemplo: el ataque a las Torres Gemelas de Nueva York, o el último episodio de alguna serie de televisión. Si ustedes hacen el ejercicio de colocar en sus cabezas, como si fueran fotos, una al lado de la otra, las memorias que tienen de su vida vana, constatarán, como me ocurre a mí, diferentes y variadas memorias que se comparten con el mundo entero.

Muchas de las imágenes son rastros de la "memoria normal", de las experiencias que viven los seres humanos en distintas partes del mundo. Sin embargo, lo que ocurre -como dicen muchos estudiosos- es que en el mundo actual (donde la cultura global es un bien de consumo, donde se propone envolver a muchas personas a través del marketing); pasamos mucho más tiempo construyendo una "memoria global común", bastante irracional, y cada vez menos tiempo construyendo nuestras "memorias locales", personales y familiares. En términos generales, lo que quiero resaltar es que uno de los riesgos más importantes de la cultura global es que no solo nos propone qué consumir sino también cómo hacerlo. El poder del gran marketing mundial captura con gran fuerza nuestra imaginación y nuestra memoria. Por eso cada individuo hace su propia interpretación, forja sus propias ideas, sensaciones y sentimientos a raíz de una canción o de un video o película; pero también está en juego la capacidad de cada uno de nosotros de reflexionar sobre su propio pasado, sobre la historia, sobre la vida, sobre la historia de la vida de nuestros amigos.

La cultura de hoy plantea un problema muy importante y, por lo tanto, debemos preguntarnos cómo recuperarnos o resistir ante ese peligro.

\section{¿Qué implica esta situación en un país como el Perú?}

Implica la necesidad de estudiar y de entender cuáles son las culturas predominantes en nuestro país. La cultura global que difunde sus contenidos a través del marketing; pero por otro lado, aquella que recibimos

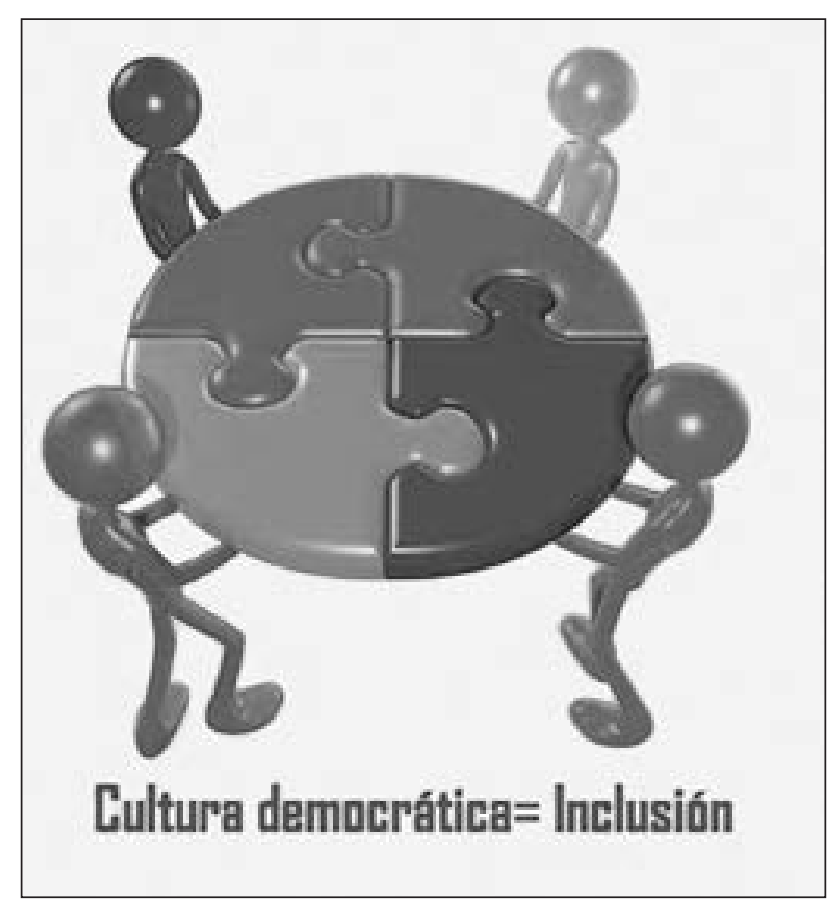

en el colegio es la que se puede llamar "cultura mestiza”, es decir, la que recibimos en la escuela, en la historia y en los medios de comunicación. Esta es una cultura basada en ciertos símbolos: la simbología republicana, la que vemos en los libros del colegio, en los libros sobre la republica, la patria, los héroes, y al lado de esta simbología un discurso sobre el mestizaje, la idea de que somos, a pesar de nuestras diferencias, un solo pueblo.

Lo que quiero sugerir es que ambas culturas, tanto la global como la mestiza, tienden a desalentar el desarrollo de esas capacidades de imaginación.

Como hemos visto, la cultura global captura nuestra imaginación con una idea bastante implícita en nuestros ideales. Pero, por otro lado, esa cultura oficial mestiza tampoco tiende a graficar una dinámica general del pasado, más bien tiende a conmover a una nación bastante estática en referencia a su pasado incaico y republicano. Según esta visión los peruanos debemos reconocer que, a pesar de nuestras diferencias de origen, compartimos una historia milenaria donde se mezclan todas las sangres.

La arqueología sostiene que la mayoría de peruanos debemos contribuir a afianzar esta cultura peruana trabajando una sola identidad cultural. Por eso esta cultura tiene problemas en absorber la complejidad de nuestra historia, de sus traumatismo, de sus rencores del pasado. Esta cultura debe profesar a toda costa la idea de confluencia, la necesidad de mirar hacia delante $\mathrm{y}$ de no retroceder demasiado en el pasado. 
Según esta perspectiva la convivencia, en una sociedad diversa y moderna como el Perú, además de respetar la comunidad debe dejar de mirar hacia el pasado y centrarse en conformar una cultura compartida hacia delante. El problema de esta postura es que pasa por alto el derecho a la identidad cultural. Somos depositarios pero también transmisores de muchas memorias simultáneas. La memoria huancaína de nuestra madre, o limeña de nuestro padre; la memoria de nuestra juventud; de nuestro barrio; del peruano; de los dos años que pasaron en Chile, etc; cada uno de nosotros percibe y transmite mucha información y, por lo tanto, cada uno de nosotros puede vivir y transmitir muchas memorias al mismo tiempo. Esto se refiere a esta libertad cultural, a esta libertad de asumir y vivir estas identidades al mismo tiempo.

Es un asunto, también, de introspección. Es decir, el esfuerzo de cada uno cuando estamos solos, hacer lo que queremos hacia adentro, pensarnos en nosotros mismos, demostrar lo que está dentro de nosotros a nivel de conversación. Esa libertad cultural es, al mismo tiempo, la libertad del arraigo, de volver a un origen si lo queremos, ya sea huancaíno, de la mamá; limeño, del papá; o del barrio donde vivieron, tal como lo hemos dicho. Es, igualmente, una libertad de desarraigo porque tiene también derecho a sentirse cercano a otra memoria, que no conocemos incluso. Porqué no tenemos derecho a volvernos muy japoneses si nos gusta muchísimo la cultura japonesa, o muy americanos si nos gusta el cine americano del oeste, si lo que se conecta con nuestra personalidad es un derecho.

En el Perú es necesario tomar conciencia del impacto que la "cultura global" y "cultura oficial mestiza" tienen para el desarrollo. En nuestro país esas reflexiones deben acrecentar, para el mayor número de personas posible, la libertad cultural, es decir, esa libertad de arraigo o de desarraigo. Para muchos esta es una idea desarrollada en otros contextos culturales, lo que, obviamente, obliga a confrontar una serie de ideas recibidas del pasado que no son valores. Por ejemplo, la idea de que para consolidar la democracia en nuestro país la cultura es secundaria, accesoria, que complementa lo elemental, que es la inclusión social, el crecimiento económico, etc. He ahí la idea de que la cultura es una decoración.

Es importante reflexionar sobre cómo la imaginación y la memoria se desarrollan en nuestro país. Nos daremos cuenta que para la posición de la democracia y del desarrollo de nuestro país no pueden ser secundaria, por el contrario, la cultura y la libertad cultural hacen que nos despertemos como ciudadanos para ser solidarios.

\section{¿Cuál es el papel de la educación?}

La educación tendría una postura bastante clara. Una de las tareas importantes en el Perú debe ser la ampliación de la libertad cultural. ¿¿Qué hace al respecto la educación? entrega cultura, por supuesto. Pero no

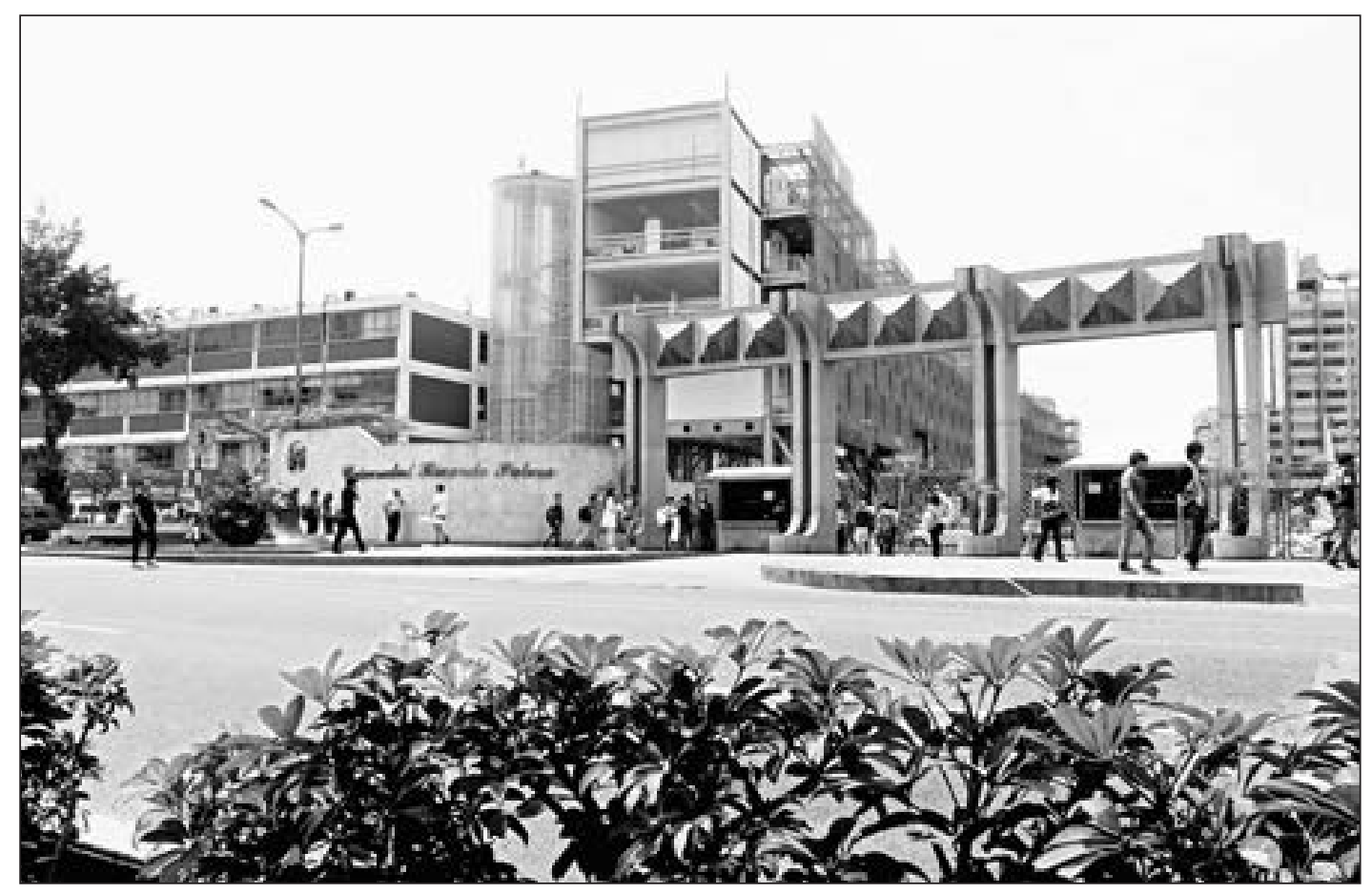


se debe entregar cultura como un bien de consumo, como un objeto que se entrega para que se abra, sino como un bien para que nos transforme, nos cambie, nos obligue a ser otra persona. La educación en nuestro país debe cultivar esas capacidades de imaginación y de memoria.

En cuanto a la imaginación -como lo sostienen todos los pedagogos- la educación debe proveer a las personas, jóvenes y adultos, de las herramientas necesarias para interpretar el mundo, para comprender la complejidad, para ampliar nuestras emociones, para acentuar la sensibilidad ante la belleza. Todo ello para mirar el mundo de otro modo, con imaginación, de una manera más personal, para ser más creativos. En consecuencia, la educación en un país como el nuestro debe ser crítica respecto a la cultura global, a sus contenidos; debe saber tomar distancia, hacer preguntas, no aceptar fácilmente sus contenidos, y en particular, debe resistir a ese ideal simplista de la libertad de la autorrealización que prometen las culturas generales globales.

Por otro lado, no hay duda de que en un país como el Perú la educación debe alentar un retorno a la memoria, es decir, una exploración crítica al pasado y un combate contra las ideologías pragmáticas que existen todavía en nuestro país. La socialización escolar debería comenzar por la enseñanza de la historia, pero también por la enseñanza del grupo neto para hacer de la enseñanza una memoria, un campo de exploración; la enseñanza de la interpretación de los sucesos del pasado, de sus vencedores y perdedores; y esto referido a la memoria familiar, personal, local y regional de cada uno de nosotros.
Educarse en la introspección quiere decir sobreponerse al temor de mirar hacia nosotros mismos, hacia nuestros recuerdos y al de nuestras familias; es sobreponerse al temor de nuestra vida.

Es importante mostrar a los niños y luego a los jóvenes que el retorno a la memoria no es un encarcelamiento sino más bien el mejor modo de decantar, de hacer clara nuestra seguridad. Por eso es importante que los adultos resistan ante la cultura oficial mestiza y rechacen todas las condicionamientos del pasado.

En resumen, la pedagogía de la imaginación y de la memoria debería tener como propósito promover la introspección y la expresión personal para hacernos mejores personas y ciudadanos.

Los estudiantes encuentran en la universidad una vía de libertad, de realización personal; es un camino para su autonomía, para que sean personas que dependen de sí mismas y no de otras. La universidad es una vía para integrar el talento y la energía, para que contribuyan al crecimiento económico en la comunidad.

Los universitarios no son un tiempo de simple consumo, de simple asimilación de contenidos, sino un tiempo para preparar la transformación como personas, y para que siendo más libres consoliden a nuestra sociedad. Reitero mi mensaje: no desperdicien su imaginación, no arrojen sus memorias, no renuncien al derecho de una mayor libertad cultural para ustedes y para todos.

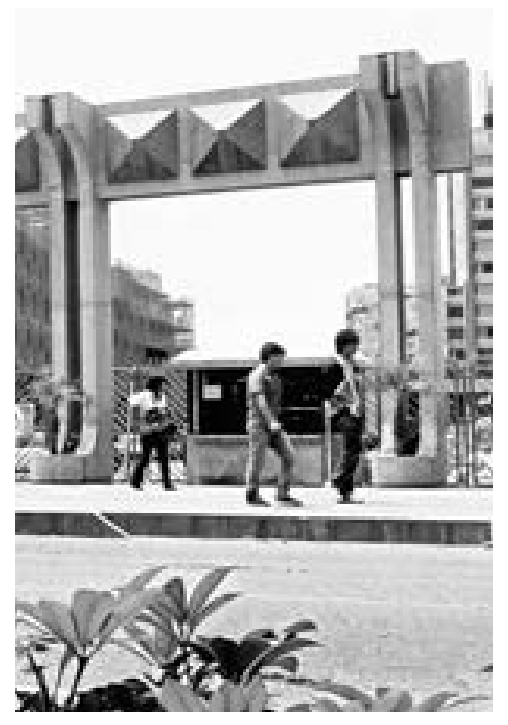

